\title{
THE IMPACT OF FOOT AND NAIL CONDITION ON FALLING, IN THE CONTEXT OF THE ELDERLY IN ACUTE HOSPITAL SETTINGS
}

\author{
R. Rokkaku, S. Kaneko
}

\begin{abstract}
This study investigates the relationship between in-patient foot and nail condition and their falling. The purpose is to determine if a nursing intervention can reduce the risk of falling in the acute hospital setting. We found that the group of those had fallen significantly suffered from abnormalities of their feet and/or nail. It became especially clear that falling was related to tinea, excessive keratin, and excessively long nails. Also, there were few nurses who were aware that foot and nail condition are a risk factor of falling. Relatedly, their concern for the condition of patients' feet and nails was low. We recommend that nurses and patients improve the condition of feet and nails to reduce falling by the elderly in an acute hospital setting. In addition, we conclude that foot care enhances the lower extremities' physiological functions.
\end{abstract}

Key words: Falling, foot, nail, foot care, elderly, acute hospital.

\section{Introduction}

When elderly people fall down, there is a high probability that they will suffer a fracture of the femur which requires a significant amount of physical rehabilitation care to overcome.

After such a fall and fracture, the patient receives a Certification of Needed Long-Term Care

from the municipal government (1). This certification legally requires that the providing nursing care includes a safety assessment of their immediate surroundings. Critical assessment factors include, internally, patients' psychological conditions, cognitive functions, and ambulatory disorders and, externally, flooring and lighting conditions. In the acute care hospital environment, the risk of the fall heightens, because patients are in unfamiliar environments and feel confused by this and the psychological condition brought about by the onset of sudden illness. In addition, the resulting limited mobility, which usually brings on sleeplessness and apathy, introduces new physical problems (2). A 2001 Japanese government investigation on the promotion of elderly health care reported that approximately $60 \%$ of healthy elderly people have

Dokkyo Medical University School of Nursing, Home health care Nursing Aria, Japan

Corresponding Author: R. Rokkaku, Dokkyo Medical University School of Nursing, Home health care Nursing Area, Kitakobayashi Mibu-Machi, Shimotsuga-Gun Tochigi, Japan, rrokkaku@dokkyomed.ac.jp abnormalities of their feet or toenails, pain or edema of the ankle, or a disfigured foot (3). In Yamashita's findings on the feet of elderly people, abnormality of feet or toenails greatly weakens muscular strength in the legs or equilibrium. In addition, about half of the people with toenail abnormalities fell during the year of the study (4). The preventive care community in Japan focused its attention on these indications and introduced the "Foot and Toenail Care" project in 2003, raising public interest in the area of the elderly's feet and toenails. As a result, a large number of elderly people were urgently hospitalized with bone fractures from falls. Additionally, in Hospital A, there were several incident reports of falling.

\section{Purpose}

Therefore, I would like to clarify the connection between the falling of elderly patients in acute care hospitals and foot or toenail trouble, for the purpose of examining nursing interventions to the prevention of falling in hospitals.

\section{Methodology}

\section{Subjects}

Subjects were drawn from Hospital A's (see Introduction) in-patient database. The Intervention 
group was randomly selected from those patients (1) aged between 70 and 89 and (2) who had experienced a fall either before or during hospitalization. The Control group was also randomly selected from those (1) aged between 70 and 89 and (2) who had never experienced a fall.

\section{Investigation period}

The investigation took place from January 4, 2009 to April 8, 2009.

\section{The intervention}

Hospital A utilizes a «Risk of Falling Assessment Table». I observed whether nurses had checked the item «swelling; disfiguration of feet or toenails» for each patient in both the Control and Intervention groups. Then, two pairs of nurses from our team observed and photographed the feet and toenails of each patient in the Control and Intervention groups, respectively. Each pair of nurses jointly assessed each patients' feet and toenails and questioned them about their feet and toenail selfcare habits. Afterwards, using each patient's photos, the four nurses re-checked our initial assessments. The items checked about the feet or toenails can be seen in Table 1: nail thickening and discoloration, an atrophied toe missing its nail, tinea, excessive keratin, an ingrown nail, excessively long nails, Valgus hallux or a varus little toes, edema or numbness of below the knees (5).

\section{Analysis}

I transcribed one item from Hospital A's «Risk of Falling Assessment Table» to our assessment sheet, then performed simple tabulation. Then, I divide that data into «Patients who had fallen» and «Patients who had not fallen» and calculate the ratio. Next, I examined it with Fisher's exact test, in order to validate the contingency table. Observation data, based on the eight items of the observation check (Table 1), were noted as Yes/No for each patient and recorded on foot diagrams (Figure 1). Finally, each subject's Yes/No responses to the feet and toenail self-care habits populated a new table, the results of which were used to find ratios per item between the two groups.

\section{Ethical procedure}

Regarding ethical considerations, the IRB of Hospital A-approved the protocol of the study.

\section{Results}

The Intervention group had 47 people (23 men, 24 women). Their average age was $79.7 \pm 8.72$. The Control group had 40 people (33 men, 7 women), with an average age of $72.6 \pm 7.15$.

Figure 1

Entry sheet

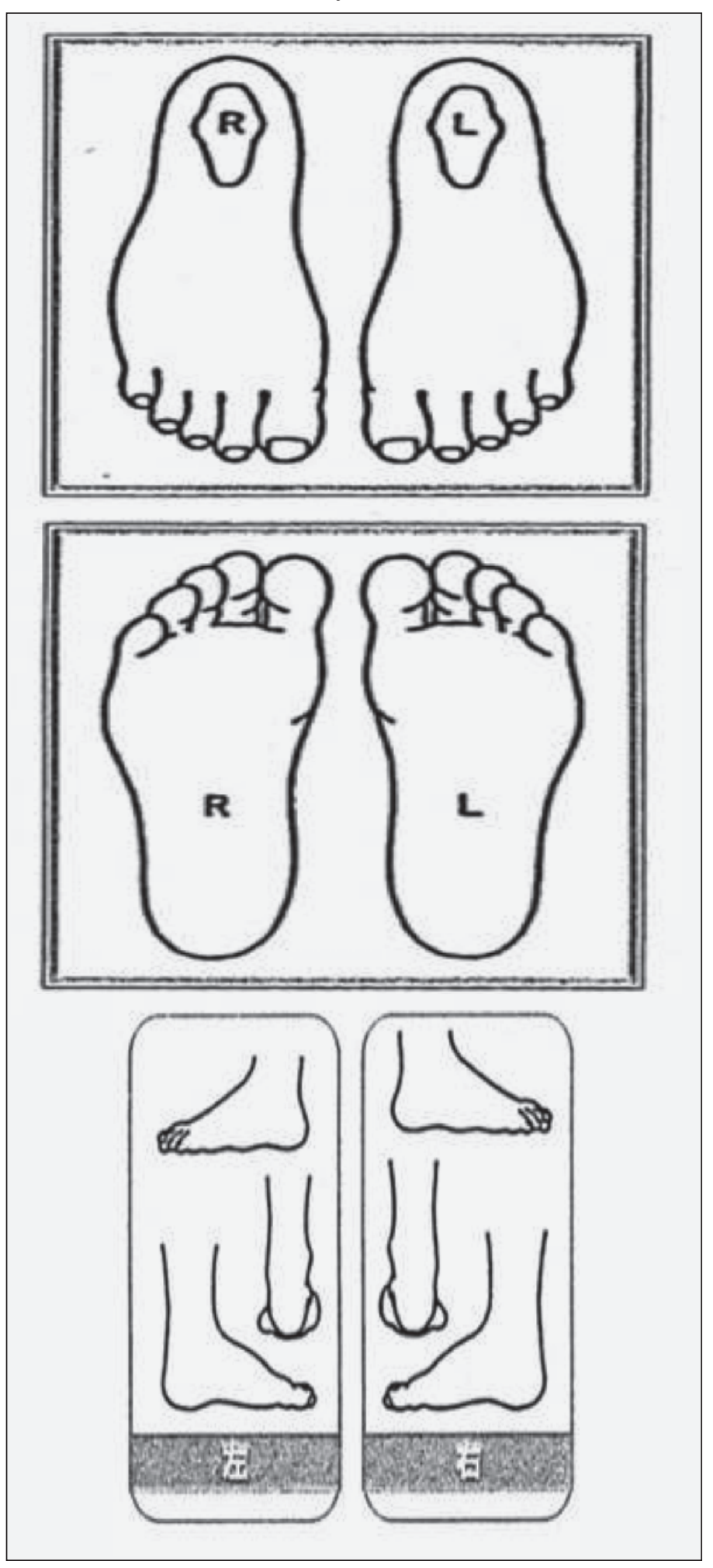




\section{Table 1}

\begin{tabular}{llll}
\hline $\begin{array}{l}\% \text { of inpatients ha- } \\
\text { ving.. }\end{array}$ & $\begin{array}{c}\text { In-patients: } \\
\text { FELL (N=47) }\end{array}$ & $\begin{array}{c}\text { In-patients: } \\
\text { NEVER Fell } \\
(\mathbf{N}=40)\end{array}$ & $\begin{array}{c}\text { Statistical } \\
\text { significance }\end{array}$ \\
\hline $\begin{array}{l}\text { normal feet and nails } \\
\text { nail thickening and } \\
\text { discoloration }\end{array}$ & $15 \%$ & $48 \%$ & $\mathrm{p}<0.01^{* *}$ \\
$\begin{array}{l}\text { an atrophied toe mis- } \\
\text { sing its nail }\end{array}$ & $26 \%$ & $30 \%$ & $\mathrm{n} / \mathrm{a}$ \\
$\begin{array}{l}\text { tinea } \\
\text { excessive keratin }\end{array}$ & $36 \%$ & $\mathrm{p}<0.01^{* *}$ \\
$\begin{array}{l}\text { an ingrown nail } \\
\text { excessively long nails }\end{array}$ & $38 \%$ & $13 \%$ & $\mathrm{p}<0.01^{* *}$ \\
$\begin{array}{l}\text { Valgus hallux or a } \\
\text { varus little toe }\end{array}$ & $19 \%$ & $18 \%$ & $\mathrm{p}<0.05^{*}$ \\
$\begin{array}{l}\text { edema or numbness of } \\
\text { below the knees }\end{array}$ & $13 \%$ & $3 \%$ & $\mathrm{n} / \mathrm{a}$ \\
\hline
\end{tabular}

(Exhibit2) excessively long nails with tinea

Figure 2

Excessive keratin

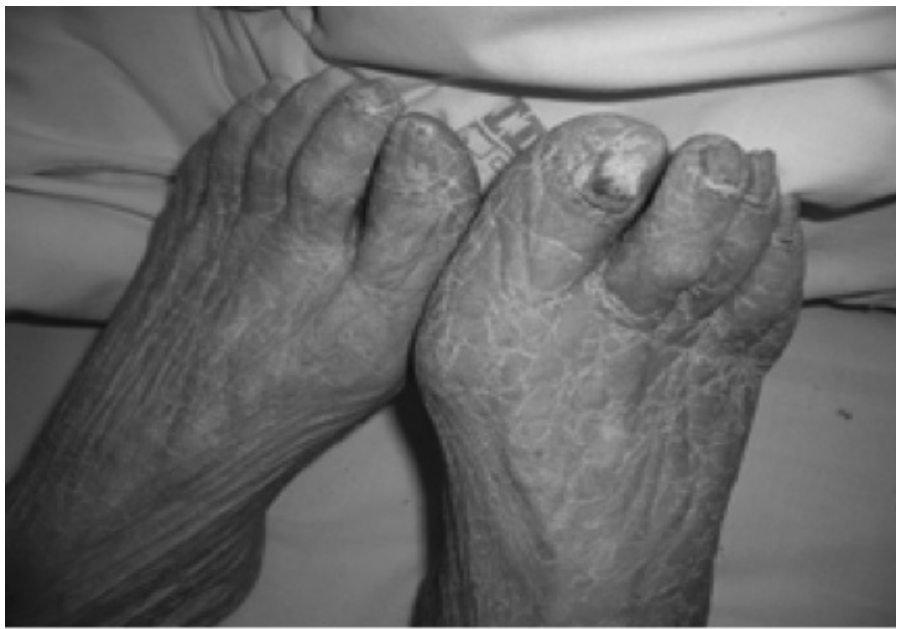

62 of 87 people, $71.3 \%$, had abnormal feet or toenails. Within just the Intervention group, the ratio increased to $85 \%$. On the other hand, the Control group's ratio was only $52 \%$. Statistical significance was recognized in both groups $(\mathrm{p}<0.01)$. Of the 62 people with abnormal feet or toenails, Hospital A's nurses had only checked 6 of the $62,9.8 \%$, for the one item from the hospital's Risk of Falling Assessment Table that directly related to foot condition: swelling; disfiguration of feet or toenails.

When questioned about their personal care, the 62 with feet or toenail problems reported receiving foot care from their families or caregivers. The remaining 25 people with normal feet and toenails had self-care habits, taking care of their own feet and toenails.

The observation results appear Table 1 and photographs of their abnormal feet and toenails show the most nail thickening and discoloration with excessively long nails (Figure 2), the most excessive keratin content
(Figure 3), and tinea with excessively long nails. (Figure 4). Four factors correlated with falling. At $\mathrm{p}<0.01^{* *}$, they were atrophied toes missing their nails, tinea, and excessively long nails. At $\mathrm{p}<0.05^{*}$, it was excessive keratin.

Figure 3

Excessively long nails with tinea

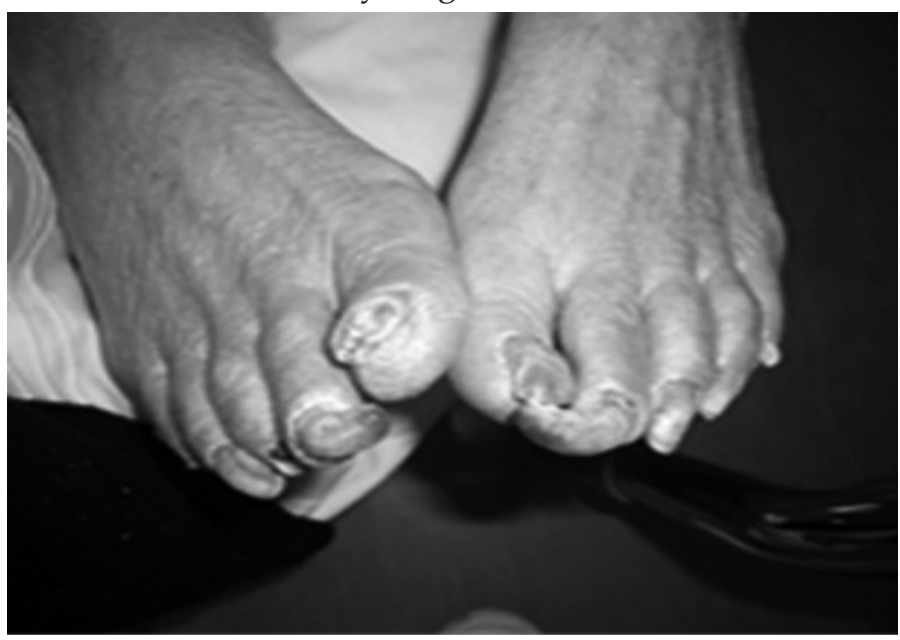

Figure 4

An atrophied toe missing its nail Valgus hallux or a varus little toe

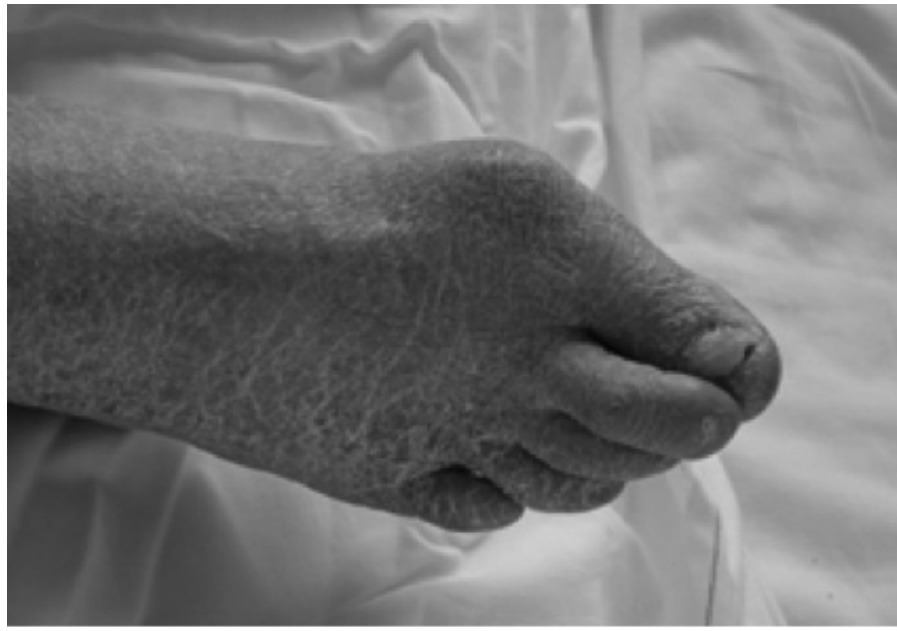

\section{Discussion}

As a majority of patients in both the Intervention and Control groups both suffer from abnormal feet or toenails, from a fall-prevention viewpoint, I have begun to focus on the foot care needs of the elderly.

\section{The issue of feet and toenail assessment}

Koski et al (1996) report that in a 2-year prospective study of 979 people 70 years or older, for those with abnormal feet or toenails the risk of falling is double (6). In addition, Barr et al (2005) report that the elderly with foot issues recognized a connection between this and 
their having fallen (7). Further, people with abnormal feet or toenails lose lower limbs muscular strength, posture control ability (8), according to Yamashita (2004). With $85 \%$ of people in the intervention group suffering from abnormal feet or toenails, it seems that elderly people tend to lose their balance or trip during while walking. Assessing their feet and toenails for fall prevention should be important.

However, as was mentioned in Methodology Intervention, these items are not checked in assessments like those used in Hospital A. There are a lot of hospitals that do not include foot or nail conditions in their "Risk of Falling Assessment" sheet. Suzuki (2009) reports, when a podiatric problem is strongly related to physical assessment, there are musculoskeletal signs in patients who have foot or nail abnormalities and who have experienced falls. However, concrete measures have not been clarified (9). It is thought that this both lowers nurses' and care providers' consciousness to the issue of feet and nails and obscures the association between falling and the issue of feet and toenails.

\section{Needs of Foot care}

We are just beginning to understand the value of foot care in preventing falling. Nurses and care providers will have to raise their interest in feet and toenails in order to grasp foot care needs via interviews and assessments. To that end, the following points are probably necessary.

Regarding fall risk assessments, add a specific item for abnormalities of the feet or toenails, then assess patients correctly.

For those patients with such abnormalities, development specific foot care regimes, such as improving the condition of the feet and toenails, including the skin and circulation, and helping choose appropriate shoes.
Promote national cooperation among relevant medical professionals, expanding awareness and treatment of the problem of feet and toenails from just hospitals to any elderly person's living environment.

\section{Conclusion}

Fall-preventive foot care is important. It is necessary to improve foot health for all of the elderly. I would like to enlighten health professionals and caregivers on why and how to care for feet in order to prevent falling.

Acknowledgement: I would like to thank the patients in the Intervention and Control Groups and the staff of Hospital A.

Conflicts of Interest: None.

\section{References}

1. Ministry of Health, Labor and Welfare of Japan. "National Life Survey 2013". Ministry of Health, Labor and Welfare of Japan. 2014. Cited 6 September 2014. http: / / www.mhlw.go.jp/toukei/saikin/hw/k-tyosa/k-tyosa13/dl/05. pdf

2. Aketa M., Teshima M., et.al. "Re-evaluation of the fall risk in acute hospital in-patients". Journal of Hospital Management, 2007. Vol. 44. 4:19-26.

3. Research Committee on Foot Care. Committee Report. Ministry of Health, Labor and Welfare of Japan. 2001.

4. Yamashita K. Obstacles to foot and nail care for the elderly. GPnet; 2003;7:2254.

5. Miyagawa H.“Medical foot care techniques”. Tokyo: Japan Nursing Association Publication Society, 2003;p. 34-35.

6. Koski K. et al. "Factors and medications as predictors of injurious falls by elderly people: A prospective population-based study. Age and Aging, 1996; 25(21):29-38.

7. Baar E.L.M. et al. "Foot and leg problems are important determinants of functional status in community-dwelling older people". Disability and Rehabilitation 2005;27(16):918-923.

8. Yamashita K. et al. "The influence on falling of foot or toenail abnormalities in the elderly". Institute of Electrical Engineers of Japan, 2004;124(10):20572063.

9. Suzuki M. The significance of the fall prevention study in the nursing study and future problem; Journal of the Nursing Study 2009;42(3)166-167 